\title{
Anterior segment-OCT findings in lacteocrumenasia
}

\section{Hallazgos en OCT de segmento anterior en lacteocrumenasia}

\author{
Ignacio García-Basterra ${ }^{1 *}$, José Díaz-Bernal ${ }^{1}$ and José Mora-Castilla²
}

${ }^{1}$ Ophthalmology department, Virgen de la Victoria University Hospital; ${ }^{2}$ Antonio Moreno Ophthalmology Clinic. Malaga, Spain

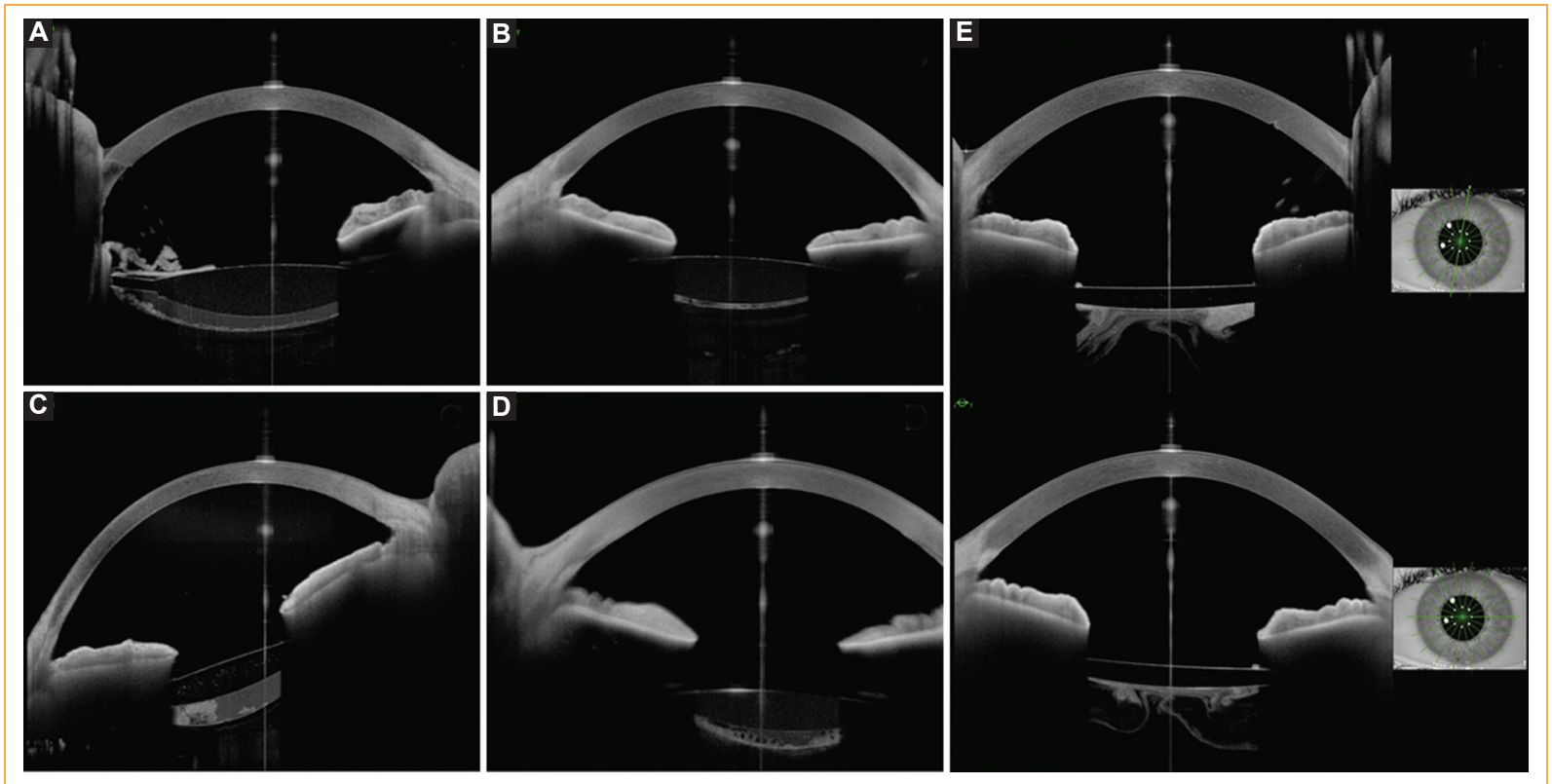

Figure 1. Anterior segment optical coherence tomography (AS-OCT) of five different cases of lacteocrumenasia.

A, B, C and D: Various presentations of lacteocrumenasia are observed, with different thicknesses and opacification patterns. D: A pseudo cystic pattern of opacification is identified in the most posterior part of the bag. E: Aspect of a case of lacteocrumenasia seconds after posterior capsule rupture with YAG laser.

We present the images of five cases of lacteocrumenasia that manifested as a visual acuity decrease several months after cataract surgery (Fig. 1). Lacteocrumenasia is the accumulation of aseptic material with a milky appearance between the posterior aspect of the intracapsular lens and the posterior capsule. ${ }^{1}$ Its usual clinical presentation is a visual acuity decrease with an image of posterior capsule opacity by

\section{Correspondence:}

*Ignacio García-Basterra.

Hospital Virgen de la Victoria

Campus Teatinos, s/n

Date of reception: $12-05-2020$

C.P. 29010, Malaga, Spain

E-mail: ignaciobas@ @otmail.com
Date of acceptance: 30-06-2020 DOI: 10.24875/RMOE.M20000131
Available online: 09-11-2020 Rev Mex Oftalmol (Eng). 2020;94(6):262-263

www.rmo.com.mx 2604-1731/@ 2020 Sociedad Mexicana de Oftalmología. Published by Permanyer. This is an open access article under the CC BY-NC-ND license (http://creativecommons.org/licenses/by-nc-nd/4.0/). 
slit-lamp examination. Anterior segment optical coherence tomography (AS-OCT) helps in an objective and non-invasive way to identify this disorder.

\section{Conflicts of interest}

The authors declare no conflict of interest and not receiving any funding for this work.

\section{Ethical disclosures}

Protection of human and animal subjects: The authors declare that the procedures followed were in accordance with the regulations of the relevant clinical research ethics committee and with those of the Code of Ethics of the World Medical Association (Declaration of Helsinki).

Confidentiality of data: The authors declare that they have followed the protocols of their Institution on the publication of patient data.

Right to privacy and informed consent: The authors have obtained the written informed consent of the patients or subjects mentioned in the article. The corresponding author is in possession of this document.

\section{References}

1. Kim, HK, Shin JP. Capsular block syndrome after cataract surgery: clinical analysis and classification. J Cataract Refract Surg. 200834(3):357-63. 